Research Paper

\title{
Autophagy-related genes are induced by histone deacetylase inhibitor suberoylanilide hydroxamic acid via the activation of cathepsin B in human breast cancer cells
}

\author{
Han Han ${ }^{1,2}$, Jing Li ${ }^{1}$, Xiuyan Feng ${ }^{1,3}$, Hui Zhou ${ }^{1}$, Shanchun Guo ${ }^{4,5}$ and Weiqiang Zhou ${ }^{1}$ \\ ${ }^{1}$ Key Laboratory of Environmental Pollution and Microecology of Liaoning Province, Shenyang Medical College, Huanggu, \\ Shenyang City, Liaoning Province 110034, P. R. China \\ ${ }^{2}$ Department of Biochemistry and Molecular Biology, Shenyang Medical College, Huanggu, Shenyang City, Liaoning Province \\ 110034 , P. R. China \\ ${ }^{3}$ The Second Affiliated Hospital of Shenyang Medical College, Heping, Shenyang City, Liaoning Province 110002, P. R. China \\ ${ }^{4}$ RCMI Cancer Research Center, Xavier University of Louisiana, New Orleans, LA 70125, USA \\ ${ }^{5}$ Department of Chemistry, Xavier University of Louisiana, New Orleans, LA 70125, USA \\ Correspondence to: Weiqiang Zhou, email: zhouwq@hotmail.com
}

Keywords: SAHA, autophagy, apoptosis, cathepsin B, cell cycle

Received: November 02, $2016 \quad$ Accepted: May 10, $2017 \quad$ Published: June 08, 2017

Copyright: Han et al. This is an open-access article distributed under the terms of the Creative Commons Attribution License 3.0 (CC BY 3.0), which permits unrestricted use, distribution, and reproduction in any medium, provided the original author and source are credited.

\section{ABSTRACT}

Autophagy is involved in modulating tumor cell motility and invasion, resistance to epithelial-to-mesenchymal transition, anoikis, and escape from immune surveillance. We have previous shown that SAHA is capable to induce several apoptosis and autophagy-related gene expression in breast cancers. However, the exact mechanisms of autophagy activation in this context have not been fully identified. Our results showed that the expression and the activity of Cathepsin B (CTSB), one of the major lysosomal cysteine proteases, were significantly increased in MDA-MB- 231 and MCF-7 cells upon SAHA treatment. We confirmed that Cystatin C, a protease inhibitor, significantly inhibited the expression of CTSB induced by SAHA on breast cancer cells. We demonstrated that SAHA is able to promote the expression of LC3II, a key member in the maturation of the autophagosome, the central organelle of autophagy in breast cancer cells. However, SAHA induced LC3II expression is effectively suppressed after the addition of Cystatin $C$ to the cell culture. In addition, we identified a number of genes, as well as the mitogen-activated protein kinase (MAPK) signaling that is potentially involved in the action of SAHA and CTSB in the breast cancer cells. Overall, our results revealed that the autophagy-related genes are induced by SAHA via the activation of CTSB in breast cancer cells. An improved understanding of SAHA molecular mechanisms in breast cancer may facilitate SAHA clinical use and the selection of suitable combinations.

\section{INTRODUCTION}

Breast cancer remains as the most common malignant disease in women in the world [1]. Although multimodality treatment strategies have been proposed for eradicating breast cancer, the incidences of breast cancer have showed a sustained upward trend for many breast cancer patients, especially estrogen receptor (ER)-negative seriously threatening their health and quality of life. Patients with ER-negative breast cancer often present high degrees of malignancy, aggression, and poor prognosis despite initial responsiveness to chemotherapy [2-3].

Epigenetic processes are direct heritable changes in gene expression without involving direct changes to the DNA sequences and play an important role in carcinogenesis [4-6]. Both the active and silent epigenetic 
genes are controlled by the processes of addition or removal of chemical modifications in the chromatin. These modifications include a variety of post-translational histone modifications (acetylation, phosphorylation, etc.). In recent years, epigenetic genes have been reported to be acetylated in breast cancer cell lines or breast tumors and most of them play critical roles in cell-cycle progression, differentiation, apoptosis, and autophagy [7-11].

Suberoylanilide hydroxamic acid (SAHA, vorinostat) inhibits histone deacetylase (HDAC) activity by acting on all 11 known human class I and class II HDACs, is considered the one of the most studied pan HDAC inhibitor [12]. SAHA causes growth arrest and death in a broad variety of tumors and is approved for clinical treatments of T-cell lymphoma [12-13]. A number of studies, including ours, have demonstrated that SAHA can also be effective in the inhibition of proliferation and progression in breast cancer cell lines and in animal tumor models [14-19]. Recent studies also demonstrated that SAHA combined with ionizing radiation or glucose6-phosphate dehydrogenase inhibitor could serve as potential therapeutic strategies for breast cancer [20-21]. However, SAHA has a short half-life of $2 \mathrm{hrs}$, due to rapid hepatic glucuronidation, making it difficult to provide the level of drug exposure necessary for durable therapeutic efficacy on solid tumors. In addition, SAHA has been ineffective against solid tumors in many clinical trials and oncogenic K-ras may contribute to SAHA resistance by upregulating HDAC6 and c-myc expression in cancer cells [22].

Cysteine cathepsins, a family of eleven human cysteine proteases that is originally characterized as main players in protein turnover within lysosomes, are highly upregulated in a wide variety of tumors by mechanisms ranging from gene amplification to post-transcriptional modification [23-24]. Cathepsin B (CTSB) is one of the major lysosomal cysteine proteases that functions in protein degradation of extracellular matrix proteins, a process promoting invasion, metastasis of tumor cells and tumor angiogenesis, and high levels of CTSB are found in a wide variety of human cancers including breast cancer [25-26]. Targeting CTSB alone does not appear to abolish tumor growth, and this is probably because CTSB appears to have diverse functions and influence numerous pathways [27]. An increase in the CTSB enzymatic activity in tumor cells treated with SAHA or other HDAC inhibitors has been reported, typically in association with apoptotic programmed cell death and autophagy [28-29]. However, a number of clinical reports have shown that CTSB was overexpressed and localized to the invasive breast tumor margin, correlating with higher aggression and poorer prognosis [30-32]. It is implied that there has a balance between breast cancer invasion and death, possibly involving in CTSB regulation. Cystatin C, a CTSB inhibitor (CBi), was also detected in breast cancer cells and its interaction with CTSB may play an important role in breast cancer invasion and metastasis [33-36].
Autophagy, a lysosomal degradation process, has been shown to be involved in modulating tumor cell motility and invasion, resistance to epithelial-to-mesenchymal transition, anoikis, and escape from immune surveillance, with emerging functions in establishing the pre-metastatic niche and other aspects of metastasis [37-39]. We have demonstrated that SAHA is capable of inducing several apoptosis and autophagy-related genes expression associated with the increased expression of CTSB in breast cancer MDA-MB-231 and MCF-7 cells [19]. Some studies have also shown that SAHA induces autophagy and exhibits potent anti-proliferative activity in breast cancer cells [4042]. CTSB acts as a cysteine protease that is predominantly present in lysosomes and has hydrolytic enzyme activity and endopeptidase activity. When a large number of CTSB extravasation in lysosomes exceeds the conventional metabolic requirement of cancer cells, CTSB triggers a series of biological effects, including cell autophagy [43]. There is an important correlation between CTSB and SAHA-induced breast cancer cell autophagy. SAHA is able to induce caspase-independent autophagic cell death rather than apoptotic cell death in tamoxifen-resistant human breast cancer cells, thus SAHA-mediated autophagic cell death is a promising new strategy for the patients with tamoxifen-resistant breast cancer [44]. However, the exact mechanisms of autophagy activation in this context have not been fully identified. In light of the inferred associations between SAHA-induced autophagy and CTSB activity, we hypothesized that SAHA-CTSB may activate molecular mechanisms conducive to the autophagy in breast cancer cells. The aim of the present study is to investigate whether or not the autophagy-related genes are induced by SAHA via the activation of CTSB in breast cancer cells.

\section{RESULTS}

\section{The effect of SAHA/Cystatin C combination on the expression and the activity of CTSB}

Preliminary experiments were performed to evaluate the effects exerted by the SAHA/Cystatin C combination in MDA-MB-231 and MCF-7 cells. We first determined the expression of CTSB upon the drug treatment by western blot assay. MDA-MB-231 or MCF-7 cells were co-cultured in the presence of Cystatin $\mathrm{C}$ at $0-100 \mathrm{ng} /$ $\mathrm{ml}$ of varying concentrations and SAHA, respectively. The results revealed that the expression of CTSB were significantly increased in MDA-MB- 231 and MCF-7 cells when Cystatin $\mathrm{C}$ was $0 \mathrm{ng} / \mathrm{ml}$, which indicated that SAHA increased the expression of CTSB. After quantitation of the integrated intensity of the images by ImageJ software, the CTSB levels increased by 6.5 - folds in MDA-MB-231 cells and 1.5- folds in MCF-7 cells, respectively (Figure 1A,C, lower panels). It is noted that Cystatin $\mathrm{C}$ at $100 \mathrm{ng} / \mathrm{ml}$ concentration, the CTSB levels were significantly lower in both MDA- MB-231 and MCF-7 cells. In contrast to MDA-MB- 231 cells, the CTSB expression in MCF-7 cells 
showed apparent dose-dependency upon SAHA/Cystatin C treatment (Figure 1A,C).

ELISA was then used to further evaluate the activity of CTSB. Similar to the expression of CTSB, the activities of CTSB were significantly increased in MDA-MB-231 and MCF-7 cells when Cystatin $\mathrm{C}$ was $0 \mathrm{ng} / \mathrm{ml}$. The activities of CTSB levels were also significantly decreased in both MDA-MB-231 and MCF-7 cells once $100 \mathrm{ng} / \mathrm{ml}$ of Cystatin $\mathrm{C}$ was added (Figure 1B,D).

\section{The effect of SAHA/Cystatin C combination on CTSB}

We then confirmed the above results using a in cell western assay. MDA-MB-231 or MCF-7 cells were incubated with SAHA $(5-10 \mu \mathrm{M})$ and different concentrations of Cystatin C (0, 20, 40, 60, 80 and 100ng/ $\mathrm{ml})$. We found that in the group with SAHA treatment, the expression of CTSB was significantly increased in both cell lines (Figure 2A,B). The CTSB levels were increased by 1.6- folds in MDA-MB-231 cells and by 2.1- folds in MCF-
7 cells. With the increased concentration of Cystatin $\mathrm{C}$, the expression of CTSB was decreased. With Cystatin C at 100 $\mathrm{ng} / \mathrm{ml}$, the levels of CTSB that reached the minimum were significantly decreased in its expression compared to SAHA treatment in both MDA- MB-231 and MCF-7 cells.

\section{The effect of SAHA/Cystatin C combination on the cell viability and apoptosis}

In order to investigate the effects of SAHA and Cystatin $\mathrm{C}$ on breast cancer cell proliferation, we determined the cell viability and apoptosis in MDAMB-231 and MCF-7 cell lines. In comparison with DMSO control treatment, both cell viability and cell number decreased in MDA-MB-231 and MCF-7 cells after SAHA treatments. While there was no significant difference between DMSO and CBi in inhibiting growth of both cell lines, the combination of $\mathrm{CBi}$ and SAHA treatment induced dramatic decreases in cell viability and cell number of both MDA-MB-231 and MCF-7 cells. (Figure 3B,C,E,F). As expected, in comparison with

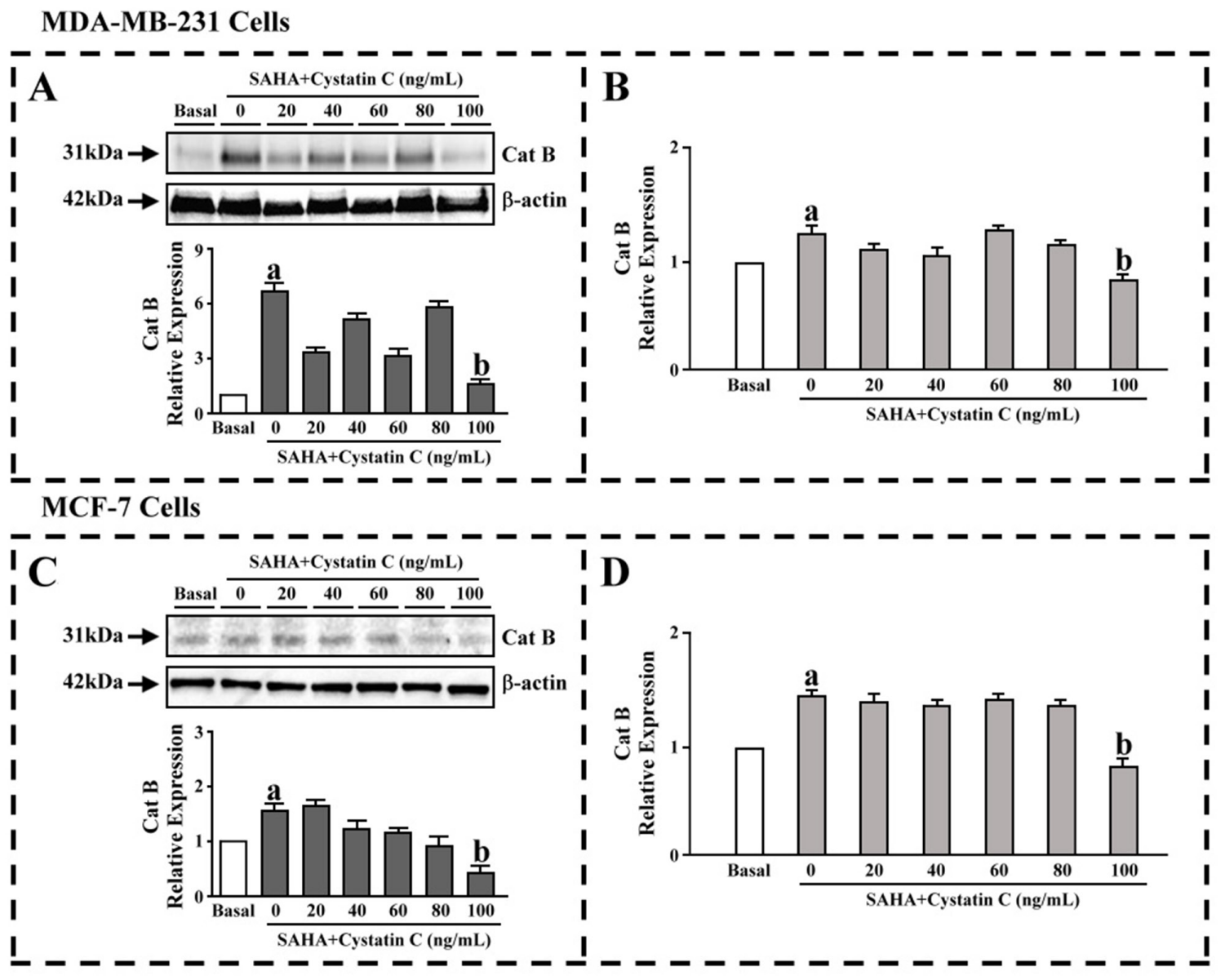

Figure 1: The effect of SAHA/Cystatin C combination on CTSB. MDA-MB-231 or MCF-7 cells were co-cultured in the presence of Cystatin C at $0-100 \mathrm{ng} / \mathrm{ml}$ of varying concentrations. (A) The CTSB levels in MDA-MB-231 cells. (B) The activity of CTSB in MDA-MB-231 cells. (C) The CTSB levels in MCF-7 cells. (D) The activity of CTSB in MCF-7 cells. (a) $p<0.05$, (b) $p<0.01$, when comparing to basal. Data (mean \pm standard error) representative results derived from a minimum of 3 independent experiments. 
DMSO control treatments, the apoptotic cells increased in MDA-MB-231 and MCF-7 cells after the SAHA treatment. $\mathrm{CBi}$ alone only showed slight increase in apoptotic cells in the two cell lines. However, the apoptotic cells dramatically increased in MDA-MB-231 and MCF-7 cells after combining $\mathrm{CBi}$ and SAHA treatment; the apoptotic rate reached $4.28 \%$ in the early stage and $21.70 \%$ in the late stage in MDA-MB-231. The apoptotic rate reached $8.10 \%$ in the early stage and $10.64 \%$ in the late stage in MCF-7 cells (Figure 3A,D).

\section{The effect of SAHA/Cystatin C combination on LC3II}

In order to clarify the effects of autophagy by SAHA and Cystatin $\mathrm{C}$ in breast cancer cells, we determined LC3II

MDA-MB-231 Cells

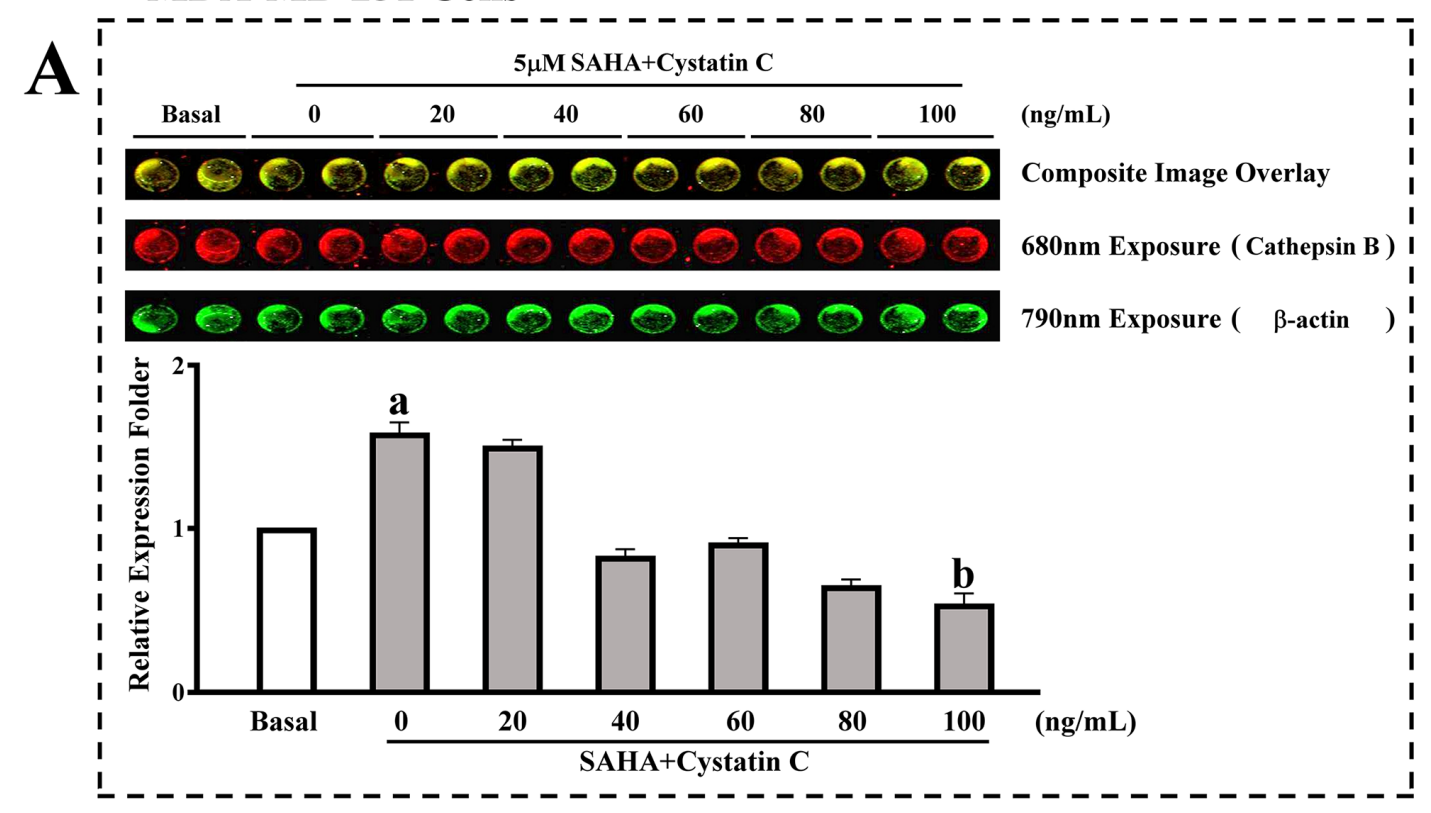

MCF-7 Cells

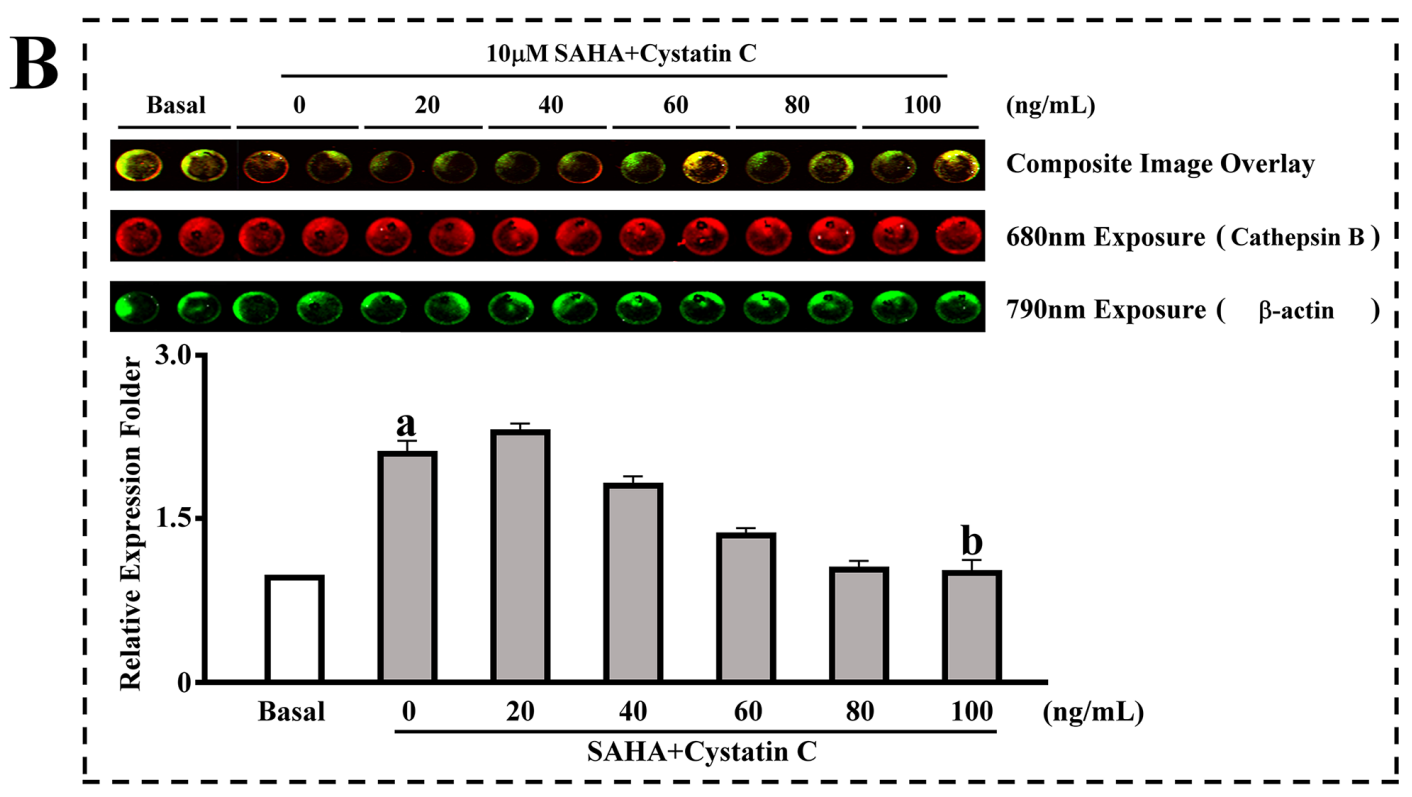

Figure 2: In cell western assay for the effect of SAHA/Cystatin C combination on CTSB. MDA-MB-231 or MCF-7 cells were incubated with $5 \mu \mathrm{M}, 10 \mu \mathrm{M}$ and different concentrations of Cystatin C. (A) The expression of CTSB in MDA-MB-231cells. (B) The expression of CTSB in MCF-7 cells. (a) $p<0.05$, (b) $p<0.01$, when comparing to basal. Data (mean \pm standard error) representative results derived from a minimum of 3 independent experiments. 
by fluorescence microscopy. The cells grew well and occupied $90 \%$ of the full plate in the control treatment of DMSO, without LC3II. On the contrary, there was a large number of LC3II in the cytoplasm of both MDA-MB-231 and MCF-7 cells after SAHA treatment. We observed distinct changes in cancer cells after $\mathrm{CBi}$ treatment alone compared to in combined SAHA treatment. For MDAMB-231 cells, there was a little LC3II after CBi treatment alone, and some LC3II after CBi plus SAHA treatment. For MCF-7 cells, there was no LC3II in the cytoplasm (Figure 4).

\section{The effect of SAHA/Cystatin C combination on the expression of autophagy-related molecules in cancer cells}

To investigate the potential involvement of signaling mechanisms in proliferation and inhibition, as well as autophagy induction by SAHA and CTSB for breast cancer cells. We used real-time PCR arrays to determine the expression levels of the genes. We found that, the trend of $\mathrm{CBi}$ and SAHA treatment combination is similar to SAHA alone, which is opposite to $\mathrm{CBi}$ alone. For MDAMB-231 cells, there were 4 genes upregulated and 1 gene downregulated after the treatment with $\mathrm{CBi}$ and SAHA, LC3A level was increased by 3.1-folds. For MCF-7 cells, there were 6 genes upregulated and 2 genes downregulated after treatment with CBi and SAHA, ATG9B, LC3A and LC3B levels were increased by over 2.5-folds (Figure 5).

To further confirm the effects of SAHA and CTSB on autophagy, we used western blot to examine the expression of ATGs and LC3. For MDA-MB-231 cells, SAHA only significantly increased ATG4A, ATG4B, ATG9B and LC3II. CBi only significantly decreased ATG4A and ATG4B. SAHA and CBi significantly increased ATG9B and LC3II. For MCF-7 cells, SAHA

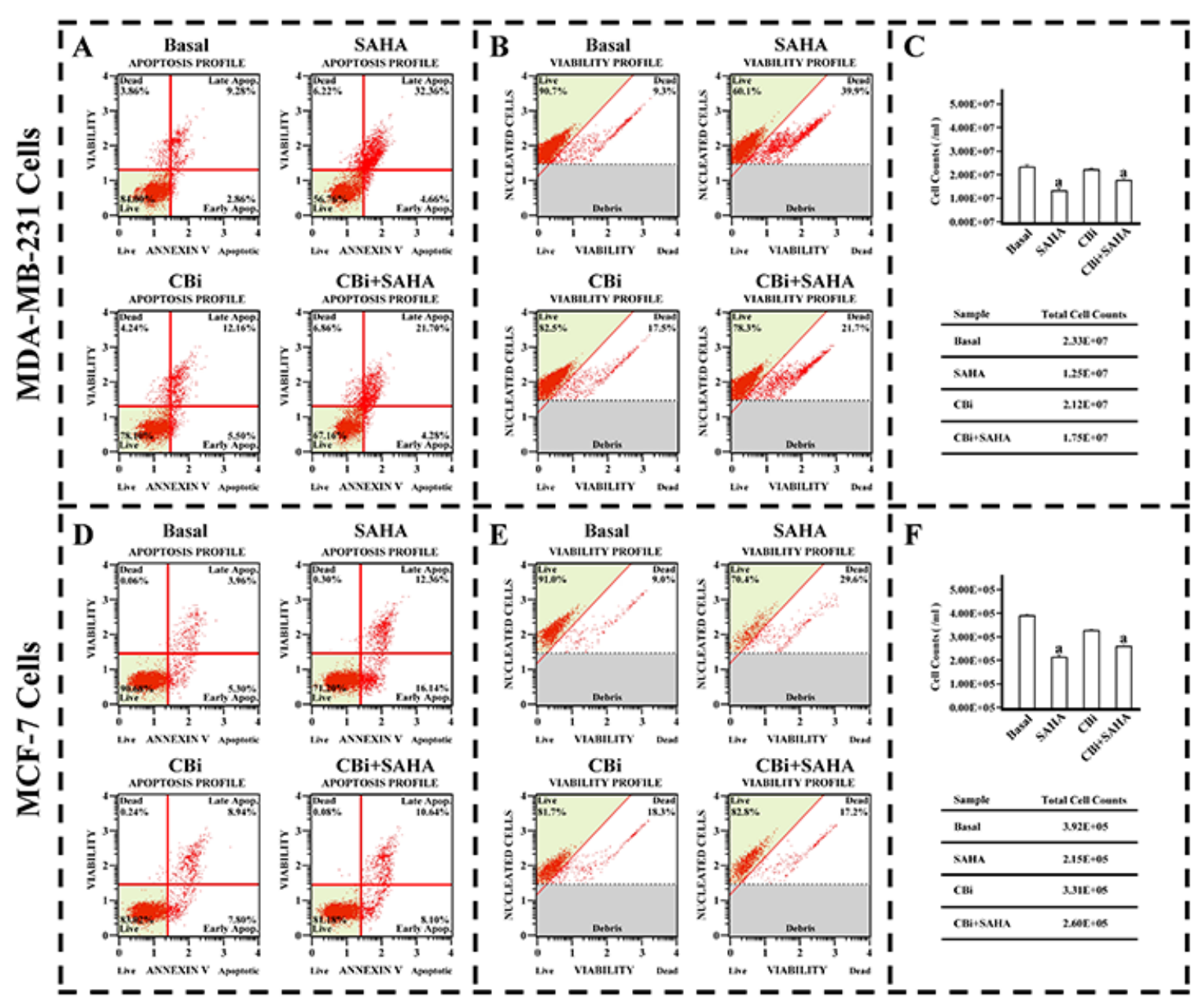

Figure 3: The effect of SAHA/Cystatin C combination on cell viability and apoptosis of cancer cells. MDA-MB-231 or MCF-7 cells were plated in 6-well plate. $5 \mu \mathrm{M}$ SAHA and $100 \mathrm{ng} / \mathrm{ml}$ Cystatin C in treatment of MDA-MB-231 cells. $10 \mu \mathrm{M}$ SAHA and 100 $\mathrm{ng} / \mathrm{ml}$ Cystatin $\mathrm{C}$ in treatment of MCF-7 cells. (A) The apoptosis profile in MDA-MB-231. (B) The cell viability profile in MDA-MB-231. (C) The cell number in MDA-MB-231. (D) The apoptosis profile in MCF-7. (E) The cell viability profile in MCF-7. (F) The cell number in MCF-7. (a) $p<0.05$, when comparing to basal. Data (mean \pm standard error) representative results derived from a minimum of 3 independent experiments. 
only significantly increased ATG4A, ATG9B and LC3II. CBi only significantly decreased ATG4A and LC3II. SAHA and CBi significantly increased ATG4A and ATG9B (Figure 6).

\section{The effect of SAHA/Cystatin C combination on the MAPK signaling}

In order to clarify the MAPK signaling mechanisms induced by SAHA and CTSB, we determined a number of protein expression using an antibody array. We found that the trend of $\mathrm{CBi}$ and SAHA treatment is similar to $\mathrm{CBi}$ alone, which is opposite to SAHA alone. For MDAMB-231 cells, SAHA only significantly decreased ERK1, ERK2, p70S6 and TOR. CBi only significantly increased AKT1, ERK1, ERK2, p70S6, RSK2 and TOR. SAHA and CBi significantly increased ERK1, ERK2, RSK2 and TOR. For MCF-7 cells, SAHA only significantly decreased AKT1, ERK1, ERK2, p70S6 and TOR. CBi only significantly increased ERK1, ERK2, p70S6 and TOR. SAHA and CBi significantly increased AKT1, ERK1, ERK2, p70S6, RSK2 and TOR (Figure 7).

\section{DISCUSSION}

We have demonstrated in previous report that SAHA is able to induce growth arrest and promoted apoptosis in breast cancer cells [19]. CTSB has a prominent function in mediating apoptosis potentiated by sodium butyrate (an HDACi), and doxorubicin combinations in myeloma [29]. In order to explore whether or not CTSB is also involved in the action of SAHA on breast cancer cells, we used western blot and ELISA assay to determine CTSB protein levels in breast cancer cells upon SAHA treatment.

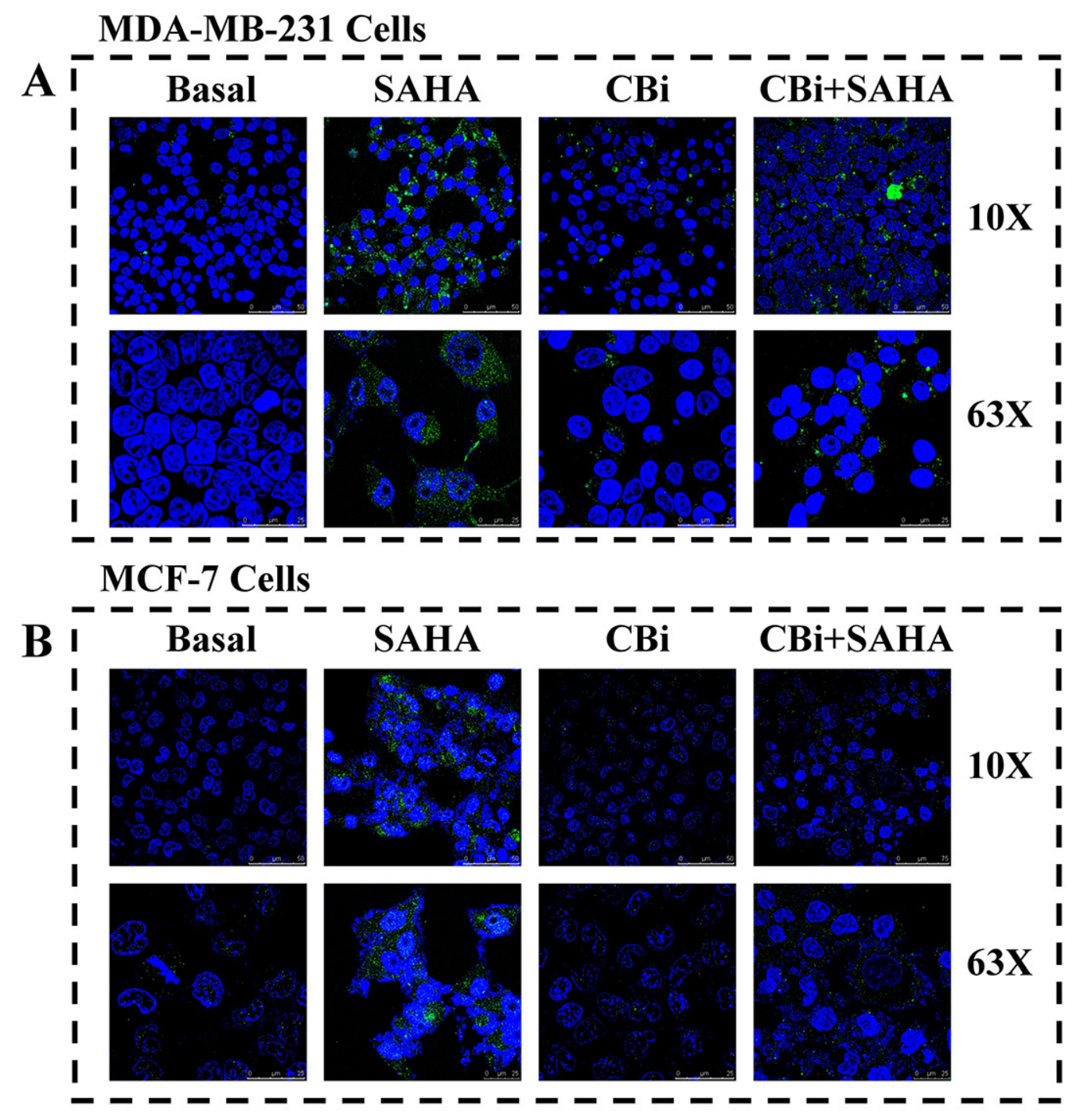

Figure 4: The effect of SAHA/Cystatin C combination on LC3II. MDA-MB-231 or MCF-7 cells were incubated with SAHA and Cystatin C in 6-well plate. $5 \mu \mathrm{M}$ SAHA and $100 \mathrm{ng} / \mathrm{ml}$ Cystatin C in treatment of MDA-MB-231 cells. 10 $\mu \mathrm{M}$ SAHA and $100 \mathrm{ng} / \mathrm{ml} \mathrm{Cystatin} \mathrm{C}$ in treatment of MCF-7 cells. (A) The fluorescence signal of LC3II in MDA-MB-231. (B) The fluorescence signal of LC3II in MCF-7. 


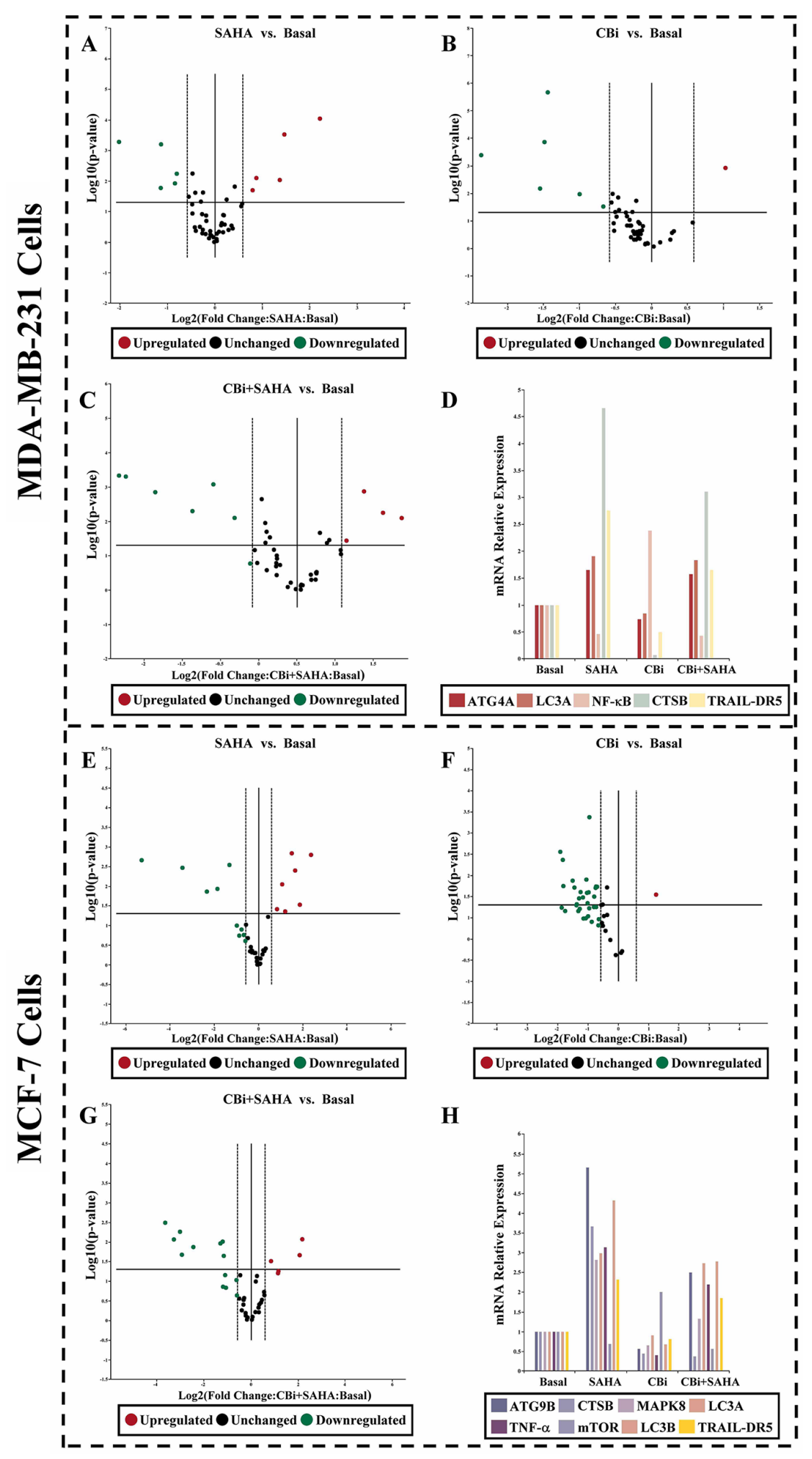

Figure 5: The effect of SAHA/Cystatin $C$ combination on the expression of autophagy-related molecules in cancer

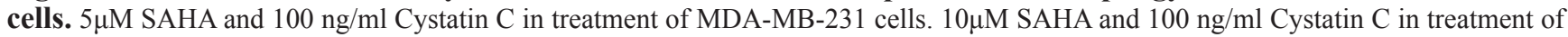
MCF-7 cells. Applied Biosystems 7500 real-time PCR system following manufacturer's instructions. (A-D) The identified genes in MDAMB-231 cells. (E-H) The identified genes in MCF-7 cells. (a) $p<0.05$, (b) $p<0.01$, when comparing to basal. Data (mean \pm standard error) representative results derived from a minimum of 3 independent experiments. 
Through our observation, we can see clearly that SAHA indeed is able to induce protein level expression of CTSB. This phenomenon indicates that CTSB is potentially involved in the action of SAHA on breast cancer cells. Next, we applied different concentrations of Cystatin C [45-46], a protease inhibitor and SAHA on MDAMB-231, MCF-7 cells. We found that large doses of Cystatin C (100ng / ml) were significantly inhibiting the expression of CTSB induced by SAHA. The overall level of protein expression, as shown through in cell western analysis, also confirms our observation.

To further confirm the effects of SAHA induced CTSB on breast cancer cells, we determined the apoptosis, cell viability and cell growth in MDA-MB-231 and MCF7 cell lines by using Muse flow cytometry. As can be seen from Figure 3, SAHA can significantly induce apoptosis in both MDA-MB-231 and MCF-7 cells. Cystatin C alone had minimal effects on the MDA-MB-231 and MCF-7 cells; however, the combination of Cystatin C and SAHA significantly reversed the inhibitory effect of SAHA on the growth of breast cancer cells. These results indicate that CTSB plays a significant role in regulating the action of SAHA in the inhibition of breast cancer cell growth and promotion of apoptosis.
Members of the LC3 family play a key role in the maturation of the autophagosome, the central organelle of autophagy [47-49]. LC3 precursors are proteolytically processed to form LC3I, which is distributed in the cytosol through diffusion. Upon the initiation of autophagy, the C-terminal glycine of LC3I is modified by the addition of a phosphatidylethanolamine (PE) to form LC3II, which translocates rapidly to nascent autophagosomes in a punctate distribution. In order to investigate the impacts of SAHA induced CTSB on autophagy in breast cancer cells, we checked LC3II in the cells treated with SAHA and Cystain $\mathrm{C}$ using laser scanning confocal microscopy. Our results showed that the fluorescence signal of LC3II significantly increased, indicating that there are a large number of LC3II in the cytoplasm of both MDA-MB-231 and MCF-7 cells after SAHA treatment. However, there were a little LC3II after CBi treatment alone, and some LC3II after CBi plus SAHA treatment in MDA-MB-231 cells. For MCF-7 cells, there was no LC3II in the cytoplasm after CBi treatment alone or CBi plus SAHA treatment. These results indicate that SAHA can promote the expression of LC3II in breast cancer cells. However, SAHA induced autophagy is effectively suppressed, after the addition of Cystatin $\mathrm{C}$ to the cell culture, since the

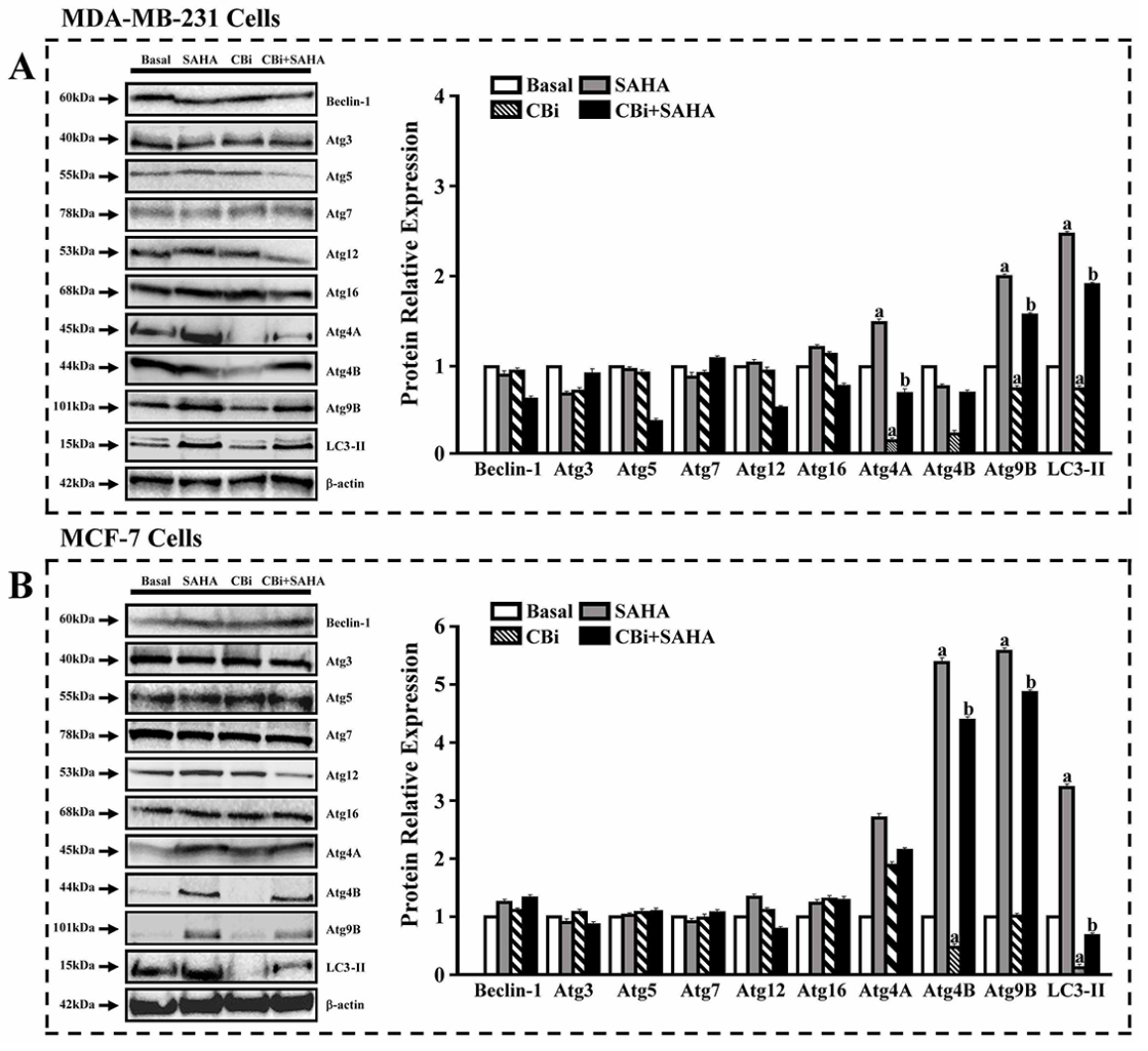

Figure 6: The effects of SAHA and Cystatin C on the expression of ATGs and LC3. Western blot analysis. 5 $\mu \mathrm{M}$ SAHA and $100 \mathrm{ng} / \mathrm{ml}$ Cystatin C in treatment of MDA-MB-231 cells. $10 \mu \mathrm{M}$ SAHA and $100 \mathrm{ng} / \mathrm{ml}$ Cystatin C in treatment of MCF-7 cells. (A) A number of proteins were validated in MDA-MB-231. (B) A number of proteins were validated in MCF-7. (a) $p<0.05$, (b) $p<0.01$, when comparing to basal. Data (mean \pm standard error) representative results derived from a minimum of 3 independent experiments. 
function of CTSB is effectively suppressed by Cystatin C, and LC3II expression significantly decreased.

To further explore the molecular mechanisms in the action of SAHA and CTSB in breast cancer cells, we used realtime PCR arrays to determine the expression levels of the genes. We identified 4 genes upregulated and 1 gene downregulated in MDA-MB-231cells after treatment with CBi and SAHA. We also identified 6 genes upregulated and 2 genes downregulated in MCF-7 cells after treatment with CBi and SAHA. SAHA and $\mathrm{CBi}$ significantly increased ATG9B and LC3II using western blot analysis in MDA-MB-231 cells. SAHA and CBi also significantly increased ATG4A and ATG9B as indicated by the western blot analysis of MCF-7 cells.

Lastly, we clarified that the mitogen-activated protein kinase (MAPK) signaling may involve in the action of SAHA and CTSB in the breast cancer cells. MAPKs are key regulators of cell growth and survival in physiological and pathological processes [50-51]. Aberrant MAPK signaling plays a critical role in the development and progression of human cancer including breast cancer, as well as in determining responses to cancer treatment [52-54]. We identified that SAHA and CBi significantly increased ERK1, ERK2, RSK2 and TOR in MDA-MB-231 cells. In contrast, SAHA and CBi significantly increased AKT1, ERK1, ERK2, p70S6, RSK2 and TOR in MCF-7 cells. The finding that SAHA and CBi are able to activate certain MAPK signaling pathways in breast cancer cells may have significant clinical values. Currently, a number of MAPK inhibitors have been developed and further explored in clinical trials of cancer patients [55-57]. The effects of SAHA combined with MAPK inhibitors need for further investigation in breast cancer.

In conclusion, our results showed that the expression and the activity of CTSB were significantly increased in MDA-MB- 231 and MCF-7 cells upon SAHA treatment. Cystatin $\mathrm{C}$, a protease inhibitor, significantly inhibited the expression of CTSB induced by SAHA on breast cancer cells. We demonstrated that SAHA is able to promote the expression of LC3II, which effectively suppressed, with the addition of Cystatin $\mathrm{C}$ to the cell culture. Additionally, we identified a number of genes, as well as MAPK signaling

MDA-MB-231 Cells
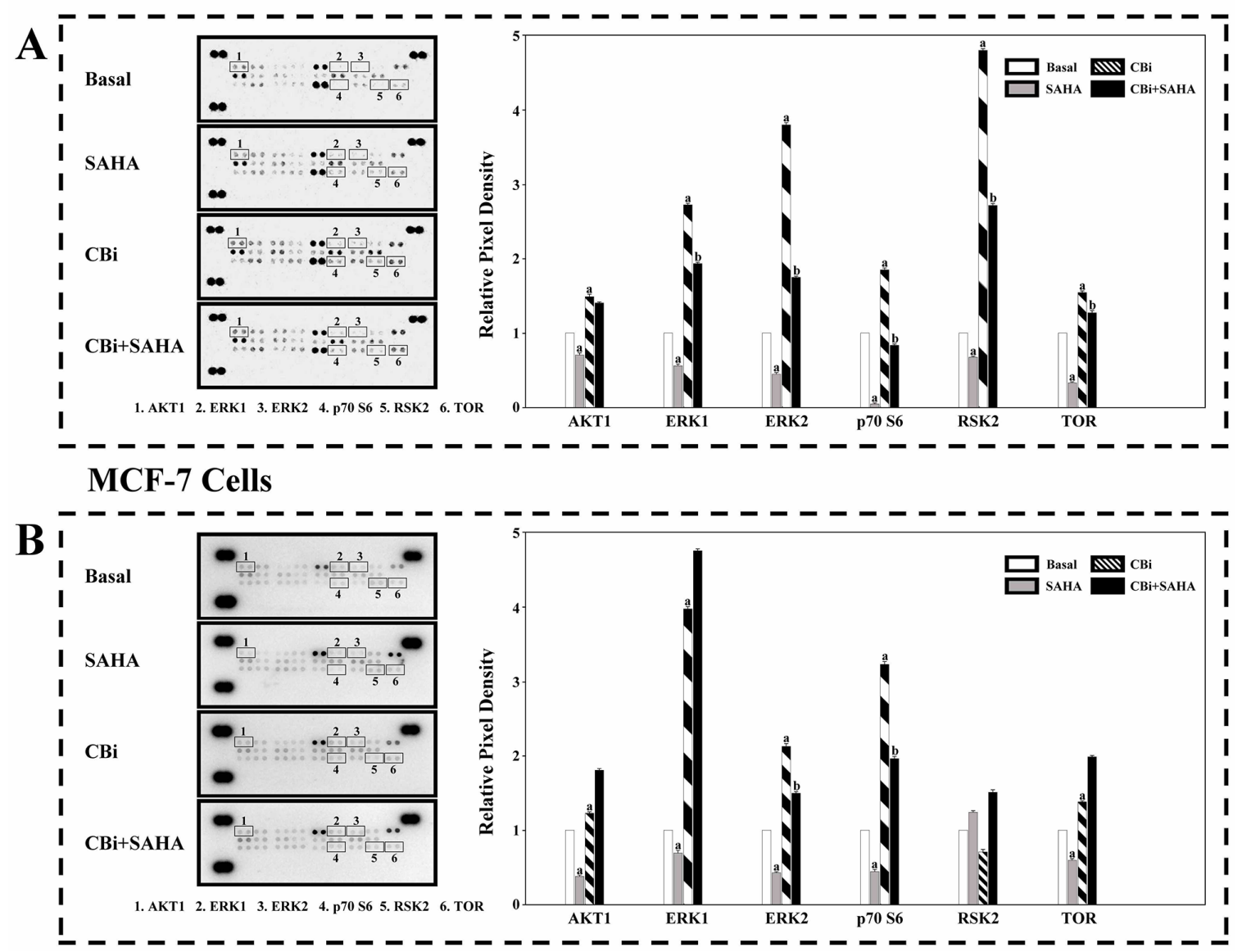

Figure 7: The effect of SAHA/Cystatin C combination on the MAPK signaling mechanisms in cancer cells. An antibody array. $5 \mu \mathrm{M} \mathrm{SAHA}$ and $100 \mathrm{ng} / \mathrm{ml}$ Cystatin $\mathrm{C}$ in treatment of MDA-MB-231 cells. $10 \mu \mathrm{M}$ SAHA and $100 \mathrm{ng} / \mathrm{ml}$ Cystatin C in treatment of MCF-7 cells. (A) A number of members in MAPK signaling were identified and their relative expression in MDA-MB-231 cells. (B) A number of members in MAPK signaling were identified and their relative expression in MCF-7 cells. (a) $p<0.05$, (b) $p<0.01$, when comparing to basal. Data (mean \pm standard error) representative results derived from a minimum of 3 independent experiments. 
that is potentially involved in the action of SAHA and CTSB in the breast cancer cells. Overall, our results revealed that the autophagy-related genes are induced by SAHA via the activation of CTSB in breast cancer cells. An improved understanding of the molecular mechanisms of SAHA action in breast cancer may facilitate SAHA clinical applications and the selection of suitable combinations.

\section{MATERIALS AND METHODS}

\section{Cell lines and reagents}

Human MDA-MB-231 and MCF-7 cells were purchased from American Type Culture Collection (ATCC) (Manassas, VA). Leibovitz's L-15 medium, RPMI-1640 medium, Fetal Bovine Serum (FBS), Penicillin-streptomycin Cocktails and Cystatin C (Catalog number: PHP0044) were obtained from Thermo Scientific (Rockford, IL). SAHA was purchased from SigmaAldrich (St. Louis, MO). Muse Cell Cycle kit, Muse Annexin \& Dead Cell kit, and Muse Count \& Viability kit were from Millipore (Darmstadt, Germany). Human MAPK Antibody Array kit was purchased from R\&D Systems (Minneapolis, MN). High Pure RNA Isolation kit and Transcriptor First Strand cDNA Synthesis kit were obtained from Roche Diagnostics GmbH (Mannheim, Germany). Exprofile Human autophagy Gene qPCR Array kit was obtained from Genecopoeia (Rockville, MD). Power SYBR Green PCR Master mix, RIPA Cell Lysis buffer and BCA Protein Assay kit were from Life Technologies (Austin, TX). Polyclonal anti-beclin-1 antibody, polyclonal anti-Atg3 antibody, polyclonal antiAtg5 antibody, polyclonal anti-Atg7 antibody, polyclonal anti-Atg12 antibody, polyclonal anti-Atg16 antibody, polyclonal anti-Atg4A antibody, polyclonal anti-Atg4B antibody, polyclonal anti-Atg9B antibody, polyclonal anti-LC3II antibody were obtained from Abcam Inc (Cambridge, MA). Protease inhibitor and other chemicals were purchased from Sigma-Aldrich (St. Louis, MO).

\section{Cell culture}

MDA-MB-231 orMCF-7 cellswere growninLeibovitz's L-15 medium or RPMI-1640 medium, respectively, with 15\% fetal bovine serum (FBS), 100U/ml penicillin and $100 \mu \mathrm{g} / \mathrm{ml}$ streptomycin. The cells were incubated in a $95 \%$ humidified atmosphere at $37^{\circ} \mathrm{C}$ with $5 \% \mathrm{CO}_{2}$. Cells were seeded in 96 -wells plate $\left(1.0 \times 10^{4}\right.$ cells $\left./ \mathrm{ml}\right), 6$-wells plate $\left(5.0 \times 10^{5}\right.$ cells $/$ $\mathrm{ml})$ and $100 \mathrm{~mm}$ dish $\left(1.5 \times 10^{7}\right.$ cells $\left./ \mathrm{ml}\right)$. Semi-confluent cells were starved for 24 hours in basal medium (with DMSO) without FBS and treated with different compounds.

\section{Cystatin C dose-response effects}

MDA-MB-231 or MCF-7 were starved as described above and incubated for 24 hours with medium containing
Cystatin C (0, 20, 40, 60, 80 and 100ng/ml). Cellular lysate were used to assess Cystatin $\mathrm{C}$ dose-response effects using western blot, ELISA and in cell western according to the manufacturer protocol.

\section{Cell viability, apoptosis and cell cycle assay}

For MDA-MB-231, cells were plated in 6-well plate. After synchronization with $5 \mu \mathrm{M}$ DMSO (basal medium) without FBS for 24 hours, the cells were incubated in complete culture medium containing $5 \mu \mathrm{M}$ SAHA or combining with $100 \mathrm{ng} / \mathrm{ml}$ Cystatin $\mathrm{C}$ for 48 hours. For MCF-7, cells were also plated in 6-well plate. After synchronization, the cells were incubated in complete culture medium containing $10 \mu \mathrm{M}$ SAHA or combining with 100ng/ml Cystatin C for 24 hours.

Muse Count \& Viability reagent was used to assess the cell viability. $2 \times 10^{5}$ of harvested cells (50ul cell suspension) was added with $450 \mathrm{ul}$ Count \& Viability reagent. The results were obtained with Muse Count \& Viability software module, and the statistics showed the concentration and percentage of viable cells.

For the apoptotic assay, $1 \times 10^{6}$ of cells were incubated with $100 \mu \mathrm{l}$ of Muse Annexin V \& Dead Cell reagent for 20 minutes at room temperature. Muse Cell Analyzer determined apoptosis, and the statistics showed the percentages of the cells represented by alive, apoptosis and dead population.

\section{RNA extraction and real-time PCR array}

RNA was extracted from MDA-MB-231 or MCF7 cells using High Pure RNA Isolation kit. First-strand cDNA, synthesized from total RNA and cDNA, was used as a template in real-time PCR reactions with Power SYBR Green PCR Master mix and was run on an Applied Biosystems 7500 real-time PCR system following the manufacturer's instructions. The $25 \mu \mathrm{l}$ real-time quantitative PCR reaction mixture consisted of $1 x$ SYBR Green Supermix and 10ng cDNA. Data normalization was based on correcting all $C_{\mathrm{t}}$ values for the average $C_{\mathrm{t}}$ values of GAPDH gene present on the array. Three independent biological replicates were performed. Quantitative PCRarray data was analyzed following the reported procedures.

\section{Western blot analysis}

MDA-MB-231 or MCF-7 cells were washed once with ice-cold PBS and disrupted by homogenization in RIPA cell lysis buffer contained $0.1 \mathrm{mg} / \mathrm{ml}$ protease inhibitor, $1 \mathrm{mM}$ PMSF. Cellular lysate was rotated for 2 hours at $4^{\circ} \mathrm{C}$ followed by centrifugation for 10 minutes at $14,000 \mathrm{~g}$ at $4^{\circ} \mathrm{C}$. Proteins were quantified using BCA protein assay kit. $20 \mu \mathrm{g}$ proteins were loaded per lane on SDS-polyacrylamide gels and transferred to PVDF membranes. Western blot analyses were performed using the antibodies described above. Level of $\beta$-actin was used 
as loading controls. Protein-bands were detected using ECL Western blot substrate and exposed on DNR MFChemi Bio-Imaging Systems.

\section{In cell western assay}

MDA-MB-231 or MCF-7 cells were incubated with SAHA and different concentrations of Cystatin C $(0,20$, $40,60,80$ and $100 \mathrm{ng} / \mathrm{ml}$ ) in a 96-well plate as described as above. $4 \%$ formaldehyde was added in $0.1 \mathrm{M}$ PBS for 20 minutes at room temperature. The cells were washed for 5 times with PBS containing $0.1 \%$ Triton X-100 for 5 minutes per wash. $150 \mu$ l blocking buffer was added into each well for 90 minutes at room temperature on a rotator. Goat anti-cathepsin B antibody (1:500 dilution) and rabbit anti- $\beta$-actin (1:2000 dilution) antibody were incubated with cells overnight at $4^{\circ} \mathrm{C}$ without shaking. After 5 times wash, donkey anti-goat Alexa Fluro 680 antibody (1:200 dilution) and donkey anti-rabbit Alexa Fluro 790 antibody (1:500 dilution) were added to each well for 1 hour incubating with gentle shaking at room temperature. The 96-well plate with SAHA and Cystatin $\mathrm{C}$ treatment was scanned to detect in both $700 \mathrm{~nm}$ and $800 \mathrm{~nm}$ channels using an odyssey infrared imaging system. The integrated intensity of the images was analyzed by ImageJ software (National Institutes of Health, $\mathrm{NIH}$ ) and the signal relative values for different treatment groups were quantified as the average $800 \mathrm{~nm}$ channel integrated intensities from duplicate wells normalized to the $700 \mathrm{~nm}$ channel signal integrated intensity.

\section{LC3II fluorescence microscopy}

MDA-MB-231 or MCF-7 cells were incubated with SAHA and Cystatin $\mathrm{C}$ in 6-well plate as indicated above. The cells were fixed with $4 \%$ formaldehyde for 10 minutes at room temperature and blocked with buffer solution containing $10 \%$ goat serum, $0.3 \mathrm{M}$ glycine, $1 \% \mathrm{BSA}$ and $0.1 \%$ tween for 2 hours at room temperature. LC3II antibody solution was added to incubate with cells overnight at $4^{\circ} \mathrm{C}$. A DyLight 488 fluoresence antibody (1:200 dilution) was used for an hour incubation period, and nuclei were counterstained with DAPI dye for another 10 minutes. The cells were imaged, and autophagy signals were visualized by fluorscence microscopy.

\section{CTSB activity assay}

MDA-MB-231 or MCF-7 cells were harvested as indicated above. Cellular lysate was gathered and the activity of CTSB was performed using the colorimetric ELISA assay according to the manufacturer's instruction. The enzymatic activity of pro-CTSB was detected by a microplate reader at $450 \mathrm{~nm}$.

\section{Human MAPK antibody array}

First, approximately $2 \times 10^{7}$ cells with SAHA and Cystatin $\mathrm{C}$ treatment were solubilized in lysis buffer.
The lysates were resuspended gently at $4^{\circ} \mathrm{C}$ for 30 minutes and centrifuged at $14000 \mathrm{~g}$ for 5 minutes. Protein concentrations of the resulting lysates were measured using a BCA protein assay kit. Next, each of antibodycoated array membranes was blocked for 1 hour. 400ug of prepared cell lysates were incubated with reconstituted detection antibody cocktail at room temperature for 1 hour. Transferred the prepared sample/antibody mixtures to each well of the dish to incubate at $4^{\circ} \mathrm{C}$ with gentle shaking overnight. The membranes were washed with wash buffer and then incubated with $2 \mathrm{ml}$ streptavidinHRP for 1 hour on a rocking platform shaker. After a final wash, membrane intensity was acquired using chemiluminescence and pixel densities can be analyzed using Gelpro Analyzer software (Media Cybernetics, Rockville, MD). Densities were measured as a percentage of the positive controls included on each membrane. After subtracting background signals and normalization to positive controls, comparisons of signal intensities among array images were used to determine relative differences in expression levels of each protein between groups.

\section{Data analysis}

Student's $t$-test was used for data analysis. Data were presented as mean \pm SEM. Values for $p<0.05$ were considered statistically significant. The model included the main effects of treatments and replicates.

\section{Author contributions}

$\mathrm{WZ}$ and $\mathrm{HH}$ participated in the design of the study; $\mathrm{HH}, \mathrm{JL}, \mathrm{XF}$ and HZ performed experiments; WZ, HH, SG analyzed data; WZ wrote the manuscript; All authors reviewed and participated in the revision of the manuscript.

\section{ACKNOWLEDGMENTS}

The work is supported by the National Natural Science Foundation of China (81172509), the Research Foundation of Science and Technology Department of Liaoning Province (2017010263), the Research Foundation of Shenyang Science and Technology Bureau (F15-199-1-28), RCMI Cancer Research Center through an NIH grant 2G12MD007595.

\section{CONFLICTS OF INTEREST}

The authors declare that they have no competing interests.

\section{REFERENCES}

1. Siegel RL, Miller KD, Jemal A. Cancer statistics, 2015. CA Cancer J Clin. 2015; 65:5-29.

2. van dVS, Smit VT, Dekker TJ, Nortier JW, Kroep JR. Discordances in ER, PR and HER2 receptors after 
neoadjuvant chemotherapy in breast cancer. Cancer Treat Rev. 2011; 37:422-430.

3. Barni S, Cabiddu M, Petrelli F. Benefit of adjuvant chemotherapy in elderly ER-negative breast cancer patients: benefits and pitfalls. Expert Rev Anticancer Ther. 2010; 10:185-198.

4. Kim HS, Kacew S, Lee BM. Genetic and epigenetic cancer chemoprevention on molecular targets during multistage carcinogenesis. Arch Toxicol. 2016; 19:19.

5. Kazanets A, Shorstova T, Hilmi K, Marques M, Witcher M. Epigenetic silencing of tumor suppressor genes: paradigms, puzzles, and potential. Biochim Biophys Acta. 2016; 1865:275-288.

6. Feinberg AP, Koldobskiy MA, Gondor A. Epigenetic modulators, modifiers and mediators in cancer aetiology and progression. Nat Rev Genet. 2016; 17:284-299.

7. Angela N, Carafa V, Conte M, Tambaro FP, Abbondanza C, Martens JH, Nees M, Benedetti R, Pallavicini I, Minucci S, Garcia-Manero G, Iovino F, Lania G, et al. c-Myc modulation \& acetylation is a key HDAC inhibitor target in cancer. Clin Cancer Res. 2016; 23:2542-2555.

8. Medler TR, Craig JM, Fiorillo AA, Feeney YB, Harrell JC, Clevenger CV. HDAC6 Deacetylates HMGN2 to Regulate Stat5a Activity and Breast Cancer Growth. Mol Cancer Res. 2016; 14:994-1008.

9. Li L, Fang R, Liu B, Shi H, Wang Y, Zhang W, Zhang X, Ye L. Deacetylation of tumor-suppressor MST1 in Hippo pathway induces its degradation through HBXIP-elevated HDAC6 in promotion of breast cancer growth. Oncogene. 2016; 35:4048-4057.

10. Wang SH, Li N, Wei Y, Li QR, Yu ZP. $\beta$-catenin deacetylation is essential for WNT-induced proliferation of breast cancer cells. Mol Med Rep. 2014; 9:973-978.

11. Lee YJ, Won AJ, Lee J, Jung JH, Yoon S, Lee BM, Kim HS. Molecular mechanism of SAHA on regulation of autophagic cell death in tamoxifen-resistant MCF-7 breast cancer cells. Int J Med Sci. 2012; 9:881-893.

12. Marks PA. Discovery and development of SAHA as an anticancer agent. Oncogene. 2007; 26:1351-1356.

13. Richon VM, Garcia-Vargas J, Hardwick JS. Development of vorinostat: current applications and future perspectives for cancer therapy. Cancer Lett. 2009; 280:201-210.

14. Chiu HW, Yeh YL, Wang YC, Huang WJ, Chen YA, Chiou YS, Ho SY, Lin P, Wang YJ. Suberoylanilide hydroxamic acid, an inhibitor of histone deacetylase, enhances radiosensitivity and suppresses lung metastasis in breast cancer in vitro and in vivo. PLoS One. 2013; 8:e76340.

15. Bellarosa D, Bressan A, Bigioni M, Parlani M, Maggi CA, Binaschi M. SAHA/Vorinostat induces the expression of the CD137 receptor/ligand system and enhances apoptosis mediated by soluble CD137 receptor in a human breast cancer cell line. Int J Oncol. 2012; 41:1486-1494.

16. Shankar S, Davis R, Singh KP, Kurzrock R, Ross DD, Srivastava RK. Suberoylanilide hydroxamic acid (Zolinza/ vorinostat) sensitizes TRAIL-resistant breast cancer cells orthotopically implanted in BALB/c nude mice. Mol Cancer Ther. 2009; 8:1596-1605.

17. Munster PN, Troso-Sandoval T, Rosen N, Rifkind R, Marks PA, Richon VM. The histone deacetylase inhibitor suberoylanilide hydroxamic acid induces differentiation of human breast cancer cells. Cancer Res. 2001; 61:8492-8497.

18. Huang L, Pardee AB. Suberoylanilide hydroxamic acid as a potential therapeutic agent for human breast cancer treatment. Mol Med. 2000; 6:849-866.

19. Zhou W, Feng X, Han H, Guo S, Wang G. Synergistic effects of combined treatment with histone deacetylase inhibitor suberoylanilide hydroxamic acid and TRAIL on human breast cancer cells. Sci Rep. 2016; 6:28004.

20. Chiu HW, Yeh YL, Wang YC, Huang WJ, Chen YA, Chiou YS, Ho SY, Lin P, Wang YJ. Suberoylanilide hydroxamic acid, an inhibitor of histone deacetylase, enhances radiosensitivity and suppresses lung metastasis in breast cancer in vitro and in vivo. PLoS One. 2013; 8:e76340. doi: 10.1371/journal.pone.0076340. eCollection 2013.

21. Debeb BG, Lacerda L, Larson R, Wolfe AR, Krishnamurthy S, Reuben JM, Ueno NT, Gilcrease M, Woodward WA. Histone deacetylase inhibitor-induced cancer stem cells exhibit high pentose phosphate pathway metabolism. Oncotarget. 2016; 7:28329-28339. doi: 28310.18632/ oncotarget.28631.

22. Wang Q, Tan R, Zhu X, Zhang Y, Tan Z, Su B, Li Y. Oncogenic K-ras confers SAHA resistance by up-regulating HDAC6 and c-myc expression. Oncotarget. 2016; 7:1006410072. doi: 10.18632/oncotarget.7134.

23. Mohamed MM, Sloane BF. Cysteine cathepsins: multifunctional enzymes in cancer. Nat Rev Cancer. 2006; 6:764-775.

24. Olson OC, Joyce JA. Cysteine cathepsin proteases: regulators of cancer progression and therapeutic response. Nat Rev Cancer. 2015; 15:712-729.

25. Aggarwal N, Sloane BF. Cathepsin B: multiple roles in cancer. Proteomics Clin Appl. 2014; 8:427-437.

26. Kos J, Mitrovic A, Mirkovic B. The current stage of cathepsin B inhibitors as potential anticancer agents. Future Med Chem. 2014; 6:1355-1371.

27. Gondi CS, Rao JS. Cathepsin B as a cancer target. Expert Opin Ther Targets. 2013; 17:281-291. doi: 10.1517/14728222.2013.740461.

28. Mitchell C, Park MA, Zhang G, Yacoub A, Curiel DT, Fisher PB, Roberts JD, Grant S, Dent P. Extrinsic pathwayand cathepsin-dependent induction of mitochondrial dysfunction are essential for synergistic flavopiridol and vorinostat lethality in breast cancer cells. Mol Cancer Ther. 2007; 6:3101-3112.

29. Cheriyath V, Kuhns MA, Kalaycio ME, Borden EC. Potentiation of apoptosis by histone deacetylase inhibitors and doxorubicin combination: cytoplasmic cathepsin B as 
a mediator of apoptosis in multiple myeloma. Br J Cancer. 2011; 104:957-967.

30. Thomssen C, Schmitt M, Goretzki L, Oppelt P, Pache L, Dettmar P, Janicke F, Graeff H. Prognostic value of the cysteine proteases cathepsins B and cathepsin L in human breast cancer. Clin Cancer Res. 1995; 1:741-746.

31. Foekens JA, Kos J, Peters HA, Krasovec M, Look MP, Cimerman N, Meijer-van GM, Henzen-Logmans SC, Evan PW, Klijn JG. Prognostic significance of cathepsins B and L in primary human breast cancer. J Clin Oncol. 1998; 16:1013-1021.

32. Maguire TM, Shering SG, Duggan CM, McDermott EW, O'Higgins NJ, Duffy MJ. High levels of cathepsin B predict poor outcome in patients with breast cancer. Int J Biol Markers. 1998; 13:139-144.

33. Yano M, Hirai K, Naito Z, Yokoyama M, Ishiwata T, Shiraki Y, Inokuchi M, Asano G. Expression of cathepsin B and cystatin C in human breast cancer. Surg Today. 2001; 31:385-389.

34. Bervar A, Zajc I, Sever N, Katunuma N, Sloane BF, Lah TT. Invasiveness of transformed human breast epithelial cell lines is related to cathepsin B and inhibited by cysteine proteinase inhibitors. Biol Chem. 2003; 384:447-455.

35. Decock J, Obermajer N, Vozelj S, Hendrickx W, Paridaens R, Kos J. Cathepsin B, cathepsin H, cathepsin X and cystatin $\mathrm{C}$ in sera of patients with early-stage and inflammatory breast cancer. Int J Biol Markers. 2008; 23:161-168.

36. Wallin H, Abrahamson M, Ekstrom U. Cystatin C properties crucial for uptake and inhibition of intracellular target enzymes. J Biol Chem. 2013; 288:17019-17029. doi: 10.1074/jbc.M113.453449.

37. Mowers EE, Sharifi MN, Macleod KF. Autophagy in cancer metastasis. Oncogene. 2016; 5:333.

38. Zhong Z, Sanchez-Lopez E, Karin M. Autophagy, inflammation, and immunity: a troika governing cancer and its treatment. Cell. 2016; 166:288-298.

39. Lin L, Baehrecke EH. Autophagy, cell death, and cancer. Mol Cell Oncol. 2015; 2:e985913.

40. Lee JY, Kuo CW, Tsai SL, Cheng SM, Chen SH, Chan HH, Lin CH, Lin KY, Li CF, Kanwar JR, Leung EY, Cheung CC, Huang WJ, et al. Inhibition of HDAC3- and HDAC6-promoted survivin expression plays an important role in SAHA-induced autophagy and viability reduction in breast cancer cells. Front Pharmacol. 2016; 7:81.

41. Zhang J, Ng S, Wang J, Zhou J, Tan SH, Yang N, Lin Q, Xia D, Shen HM. Histone deacetylase inhibitors induce autophagy through FOXO1-dependent pathways. Autophagy. 2015; 11:629-642.

42. Min A, Im SA, Kim DK, Song SH, Kim HJ, Lee KH, Kim TY, Han SW, Oh DY, O'Connor MJ, Bang YJ. Histone deacetylase inhibitor, suberoylanilide hydroxamic acid (SAHA), enhances anti-tumor effects of the poly (ADPribose) polymerase (PARP) inhibitor olaparib in triplenegative breast cancer cells. Breast Cancer Res. 2015; 17:33.
43. Marino G, Uria JA, Puente XS, Quesada V, Bordallo J, LopezOtin C. Human autophagins, a family of cysteine proteinases potentially implicated in cell degradation by autophagy. J Biol Chem. 20037; 278:3671-3678.

44. Lee YJ, Won AJ, Lee J, Jung JH, Yoon S, Lee BM, Kim HS. Molecular mechanism of SAHA on regulation of autophagic cell death in tamoxifen-resistant MCF-7 breast cancer cells. Int J Med Sci. 2012;9:881-893. doi: 10.7150/ijms.5011.

45. Xu Y, Ding Y, Li X, Wu X. Cystatin C is a diseaseassociated protein subject to multiple regulation. Immunol Cell Biol. 2015; 93:442-451.

46. Kos J, Werle B, Lah T, Brunner N. Cysteine proteinases and their inhibitors in extracellular fluids: markers for diagnosis and prognosis in cancer. Int J Biol Markers. 2000; 15:84-89.

47. Schaaf MB, Keulers TG, Vooijs MA, Rouschop KM. LC3/GABARAP family proteins: autophagy-(un)related functions. FASEB J. 2016; 30:3961-3978.

48. Wild P, McEwan DG, Dikic I. The LC3 interactome at a glance. J Cell Sci. 2014; 127:3-9.

49. Lee YK, Lee JA. Role of the mammalian ATG8/LC3 family in autophagy: differential and compensatory roles in the spatiotemporal regulation of autophagy. BMB Rep. 2016; 49:424-430.

50. Zhou X, Naguro I, Ichijo H, Watanabe K. Mitogen-activated protein kinases as key players in osmotic stress signaling. Biochim Biophys Acta. 2016; 1860:2037-2052.

51. Kim EK, Choi EJ. Compromised MAPK signaling in human diseases: an update. Arch Toxicol. 2015; 89:867-882.

52. Low HB, Zhang Y. Regulatory roles of MAPK phosphatases in cancer. Immune Netw. 2016; 16:85-98.

53. Uehling DE, Harris PA. Recent progress on MAP kinase pathway inhibitors. Bioorg Med Chem Lett. 2015; 25:4047-4056.

54. Yasuda T. MAP kinase cascades in antigen receptor signaling and physiology. Curr Top Microbiol Immunol. 2016; 393:211-231.

55. Patnaik A, Haluska P, Tolcher AW, Erlichman C, Papadopoulos KP, Lensing JL, Beeram M, Molina JR, Rasco DW, Arcos RR, Kelly CS, Wijayawardana SR, Zhang X, et al. A first-in-human phase I study of the oral p38 MAPK inhibitor, ralimetinib (LY2228820 Dimesylate), in patients with advanced cancer. Clin Cancer Res. 2016; 22:1095-1102. doi: 10.1158/1078-0432.CCR-15-1718.

56. Menzies AM, Wilmott JS, Drummond M, Lo S, Lyle M, Chan MM, Thompson JF, Guminski A, Carlino MS, Scolyer RA, Kefford RF, Long GV. Clinicopathologic features associated with efficacy and long-term survival in metastatic melanoma patients treated with BRAF or combined BRAF and MEK inhibitors. Cancer. 2015; 121:3826-38235. doi: 10.1002/cncr.29586.

57. Zaman $\mathrm{K}$, Winterhalder $\mathrm{R}$, Mamot $\mathrm{C}$, Hasler-Strub U, Rochlitz C, Mueller A, Berset C, Wiliders H, Perey L, Rudolf CB, Hawle H, Rondeau S, Neven P. Fulvestrant with 
or without selumetinib, a MEK $1 / 2$ inhibitor, in breast cancer progressing after aromatase inhibitor therapy: a multicentre randomised placebo-controlled double-blind phase II trial,
SAKK 21/08. Eur J Cancer. 2015; 51:1212-1220. doi: 10.1016/j.ejca.2015.03.016. 